\title{
Editorial
}

\section{Competition and Collaboration}

\author{
Koroku Hashimoto, M.D.*
}

\begin{abstract}
NE day during my recent trip to the United States, I had an opportunity to visit the Mayo Clinic with a young friend of mine as a guide, where I met Dr. J. D. Grabow who had stayed in Japan for two years as a reserve doctor in the American Navy. He was quite honest to show how everything is arranged for finding the cause of disorders of one patient under the collaboration of specialized doctors. There vividly lives a friendly atmosphere based on humanism in every corner. The next day I visited the Department of Physiology and the Department of Pharmacology, Medical School, University of Minnesota. Dr. Murice B. Visscher, our respected pioneer of adventures in the physiological science and a sincere educator, readily consented to show me around his Department. It was a happy moment in my life to have known the man of Dr. Victor Lorber. Dr. Fred Shideman spared his busy time for me to discuss his philosophy on building up the Department of Pharmacology. I was very happy finding fair competitions in a very friendly atmosphere in both Departments. I have gained such experiences from the Department of Pharmacology, Cornell University Medical College since my first visit in 1954.
\end{abstract}

Now no man will disagree on the philosophy of medical science: medical science is the knowledge which, present or future, must be devoted to the human welfare and its fruits must be shared indiscriminately by every person, every race and every country. This is a just and fine philosophy. However, that is no reason why we should avert our eyes from the practical daily problem. As it is inevitable for any fine philosophy to be confronted with difficulties coming from the uncertainty of human mind when any person does work enthusiastically with this philosophy for mankind, the same appears to happen to the progress of medical science not only inside the national border but also across the border. The difficulties grow more serious in more limited circles, like a medical school, a medical institute or a medical society, either intra or international, where the scientists work on more closely related projects. In any place where human being lives, the competition and collaboration are brought about by the human nature. A strong competition

* Professor of Pharmacology, Faculty of Medicine, University of Tohoku, Sendai. 
evokes stimulus while a weak one discourages high spirits. A fair competition brings about collaboration, but unfair competitions spoil friendship. We the medical scientists must not ignore the truth of the human mind in spite of the fine philosophy of medical science.

The publication of a scientific paper is one of the most practical steps for advancing medical science. As long as the publication business stays as a human task, it creates competition and collaboration among scientists, either in a good sense or a bad sense. Nowadays the publication takes time, at least six months and sometimes one year according to circumstances after the manuscripts was delivered to the editors. Up to the date of publication the reporters are not sufficiently protected from a risk of losing the priority. Unfortunately, the Japanese sicentists are troubled with a severe language barrier. As a matter of fact, to write in a foreign language is an extra burden for them. When they make a contribution to a foreign Journal or Journals written in foreign languages, a longer delay for publication is common because of necessary revision of inadequate use of words and style of expression. In other words, the Japanese scientists must pass longer periods without guarantee of the priority of the work than those who are used to presare the paper with their own language even in the modern age of increasing pressure of competition. I have had both kinds of experiences in the past: in some cases being kindly helped in publishing our work in English and in other cases losing our priority on account of the delayed publication. This circumstance makes difficult to realize in practice the original humanistic idea of medical science.

We need fair competitions for I believe that there is no real collaboration without fair competition. Although it is still a big problem of human reliance and honesty whether or not the scientists could compete and collaborate with others in a fair way, it is particularly important for the Japanese scientists to rely upon one another to protect the priority of our work, simply because the language barrier is an extra burden and handicap for all of us.

I believe that the mutual reliance based on honesty is a fundamental request for the fair competition and collaboration as the practice of humanistic science while the political advantage through negotiation and ruling is a minor share for the medical scientists. 